\title{
American Pediatric Society 2015 Presidential Address: leaky pipes, glass ceilings, and changing landscapes-time to renovate the pediatric house
}

\author{
Donna M. Ferriero ${ }^{1,2}$
}

Presented at the PAS Annual Meeting, 25-28 April 2015, San Diego, CA.

A s you know from our website, the focus of the American Pediatric Society is to advance academic pediatrics. This is accomplished through promoting pediatric research and scholarship, serving as a strong and effective advocate for academic pediatrics, recognizing and honoring achievement, and cultivating excellence, diversity, and equity in the field of pediatrics through advocacy, scholarship, education, and leadership development. These are the principles I will address.

The title of this talk is purposely named because we have issues, but they are addressable and fixable.

The problem began a century ago with the Flexner Report on Medical Education published in 1910. These recommendations nearly eliminated women from the physician workforce because of the longer periods of study, fewer schools accepting women, and a real de-emphasis on prevention and public health fields. A century later, we have a gender revolution in medicine. Women make up more than half of our entering med school classes and more than $70 \%$ of residents in pediatrics (1).

But issues remain. A report on the Status of Women Faculty in the Schools of Science and Engineering at MIT in 2011 (2) which was a follow on report from an earlier study, highlighted the importance of recognizing that childcare issues are NOT women's issues but rather gender neutral family concerns, that women do NOT have to be soft and sweet to be effective, that they can be aggressive in a positive way, that the old boys network still creates unconscious bias and that there is a real need for leadership to ensure equity in assignments and recognition.

So why is the pipeline leaky? Early lack of support will certainly create an exodus. Parenthood and especially motherhood is the next early challenge. If we do not help our young people to manage career expectations, we will lose them. Isolation and exclusion is another risk as we proceed and can certainly be addressed through networking and other measures to be discussed.

In an excellent treatise on gender and Science Technology Engineering Mathematics (STEM) education (3), Blickenstaff proposed that there is a broad array of explanations for the absence of women in STEM put forth in the literature of the last $30 \mathrm{y}$. He argued that some of these explanations are without merit and are in fact dangerous, while others do play a part in a complex interaction of factors. Are girls inadequately prepared? Do they have a poor attitude toward science that is created by lack of positive experiences in childhood? There certainly are a paucity of role models in early education that are enhanced by negative cultural pressures and an inherent masculine worldview. Perhaps a chilly climate does exist.

Unconscious bias starts early. Data exist, independent of faculty gender, scientific field, age or tenure status, that clearly show that faculty perceive women students who pursue a career in science less competent, hireable and clearly have a lack of mentoring (4).

So Blickenstaff would suggest that we work on how we teach not on who we teach or remediating women. If we ensure equal access to resources, create assignments that show how wonderful science is, use cooperativity in classroom settings, eliminate, not just avoid, sexism and sexist language and imagery, and acknowledge the political nature of scientific inquiry, we can fix this.

An interesting study was done at the University of Wisconsin to break the gender bias habit in the faculty (5). Tests were conducted in a variety of departments including science, medicine, and engineering schools. A randomized clinical trial using a $2.5 \mathrm{~h}$ workshop intervention followed by an online survey was employed. Postintervention there were significantly greater changes in the experimental group with gender equity promoting behaviors, valuing of research, and comfort in raising conflicts.

This leaky pipeline exists for scientists and physicians alike. A survey posted on the University of California Faculty Family Friendly Edge website (http://ucfamilyedge.berkeley.edu/) (6) showed that upon receipt of the $\mathrm{PhD}, 29 \%$ of women with babies are less likely to enter a tenure-track position. Marriage for women also poses a threat with $20 \%$ less entering, whereas the opposite is true for men. The big hurdle of achieving associate professorship shows another loss and it is expected that $25 \%$ of women are less likely to become full professor within a maximum of $16 \mathrm{y}$. 


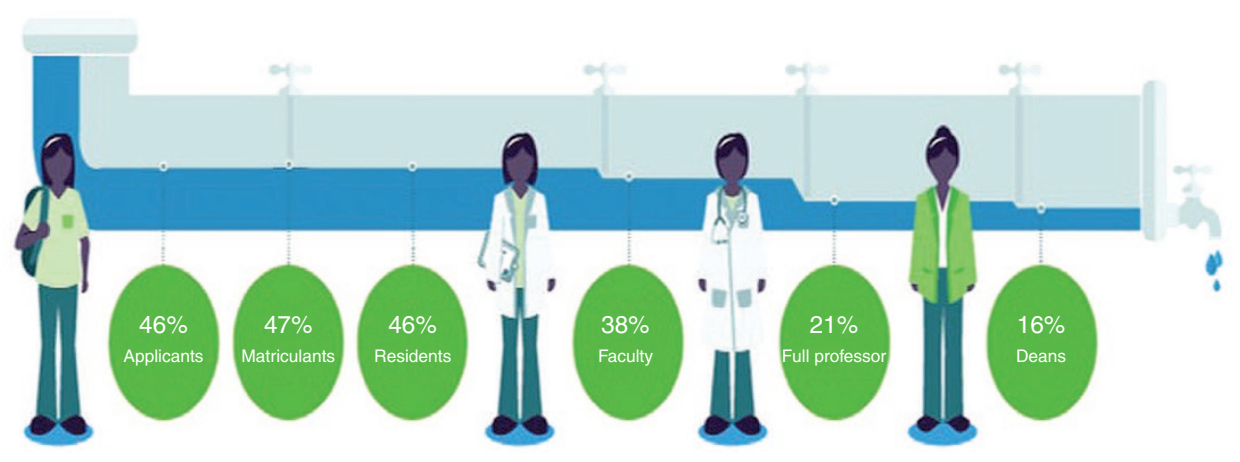

Figure 1. Data from the Association of American Medical Colleges provides a view of the pipeline from women applicants through rising through the ranks to deanship. Reprinted with permission from the Association of American Medical Colleges.

Our grant structuring creates some of the problem. The report from the Physician Scientist Workforce Working Group illustrates the issues (7). Early awards are often institutional and in order for physician scientists to advance in clinical training and fellowship they need exposure, mentoring and further education, often again supported by institutional funding. But the allure of clinical practice and industry research counterbalance the fear of mounting debt. The ability to achieve $\mathrm{K}$ status is sometimes inhibited by this debt as well as burdensome regulatory requirements and the time needed to prepare successful applications. The transition to independent investigator and senior faculty really does depend on National Institute of Health (NIH) success rate, and the ability to find protected time and be bolstered by institutional support. Even in the face of success at this level, we lose people from science to more traditional academic or government roles in administration. The report clearly highlights an existing stagnation in the workforce with a flat reporting of physicians who state that research or education is their primary practice area. Over the past decade, the total number has climbed insignificantly.

But hope springs eternal! Peggy Hostetter shared from the Physician Scientist Development Program MDPhDs who were selected by the program achieved $100 \%$ success rate in their next grant application, and MDs selected also fared much better than those not selected for the program.

Let us focus a bit on advancement in the pipeline. Data from the State of Women in Academic Medicine from the Association of American Medical Colleges (AAMC) in 2014 show diminishing numbers of women as we rise through the ranks remembering that over half of our medical students are women (Figure 1) (8).

In this graphic representation from that report, we can see the breakdown clearly. Overall men make up $62 \%$ of full time faculty and women only $38 \%$. Women are represented in the light green shades and show fewer numbers at each stage except instructor.

Taking a closer look over time, a decade ago we had equal numbers of instructors but as women move up the academic ladder, their numbers are less than men at all stages. There has
Table 1. Gender distribution for 2014 in the American Pediatric Society and Society for Pediatric Research

\begin{tabular}{lc}
\hline American Pediatric Society membership_Active & $n$ \\
\hline Male & 1,356 \\
Female & 446 \\
\hline Society for Pediatric Research membership_Active & $n$ \\
\hline Male & 579 \\
Female & 500 \\
\hline
\end{tabular}

been a significant increase of 7 percentage points at the full professor level which encourages us that we are moving in a positive direction, albeit at glacial speed.

What about leadership? A recent Analysis in Brief from the AAMC in February of this year shows that over the decade women are making modest gains at the departmental level, less so in the dean rankings and a bit higher in the full medical dean positions (9).

Well, we might end up asking the question: Can we have it all? Does a family preclude a career? Is it possible to be a CEO, have a partner, raise perfect kids, enjoy an amazing sex life, go to Pilates, and keep up with your book club? Ms. Moneypenny says that time is a scarce resource and we have to make choices at different points in our life, so "all" may not exist simultaneously. By the way, this book, Career advice for ambitious women is a page-turner! (McGregor H. "Mrs Moneypenny's Careers Advice for Ambitious Women”, Viking Press 2012) (10).

In order to fix the leaks in our pipeline, we have to have a light at the end of that tunnel which cannot be obscured by the glass ceiling. How do we break through that ceiling? We do it by embracing risk. We take chances on that pregnant woman who is exceptionally bright but has to balance family and work issues.

Lets take a look at our societies. The American Pediatric Society membership continues to be male dominant. However, hope remains. The Society for Pediatric Research membership, discounting the older emeriti and seniors, shows a wonderful 
balance in active members and even more women fellows than men (Table 1).

Nine percent of the American Pediatric Society presidents have been women beginning in 1948, with quite a few gaps. Our Howland Award has recognized women- now 14\% of awardees are women including the past $3 \mathrm{y}$.

Dr. Cathy DeAngelis just published a report in JAMA Pediatrics on Women in Pediatrics. There is a table showing the women pediatric department chairs and their affiliations, not an exceptionally long list (11).

So the landscape is changing dramatically. There is not only a serious drought in California, but our resources are drying up and we need to proactively search for solutions. This is really a national and global issue. From an excellent monograph from the American Academy of Arts and Sciences, we see these alarming data. The US has fallen to 10th place globally in Rand D investment over the past two decades (12).

In a letter to Vannevar Bush, then President Franklin D Roosevelt wrote: "New frontiers of the mind are before us, and if they are pioneered with the same vision, boldness and drive with which we have waged this war we can create a fuller and more fruitful employment and a fuller and more fruitful life" (12). The path to the endless frontier is clear but America does not seem to be on it.

How do we get the United States back on track? Should federal obligations for basic research flatline relative to economic growth, the United States will by 2032 have accumulated a $\$ 639$ billion shortfall, in federal support of basic research relative to the 4.4 percent average annual real growth trend established during the period of 1975-1992. The American Academy of Arts and Sciences recommends that the nation return to this historical competitive growth rate with the ultimate goal of fully closing the basic research shortfall as the economy continues to improve.

In a FASEB report (2015) on sustaining discovery in biologi$\mathrm{cal}$ and medical sciences, hope is provided by a number of recommendations (13).

First, we obviously must maximize research funding by sustaining it and optimizing resources that could reduce the regulatory burdens. Resource sharing will also contribute. We must optimize funding mechanisms such as greater use of just-in-time, increased funding periods, and a prioritization

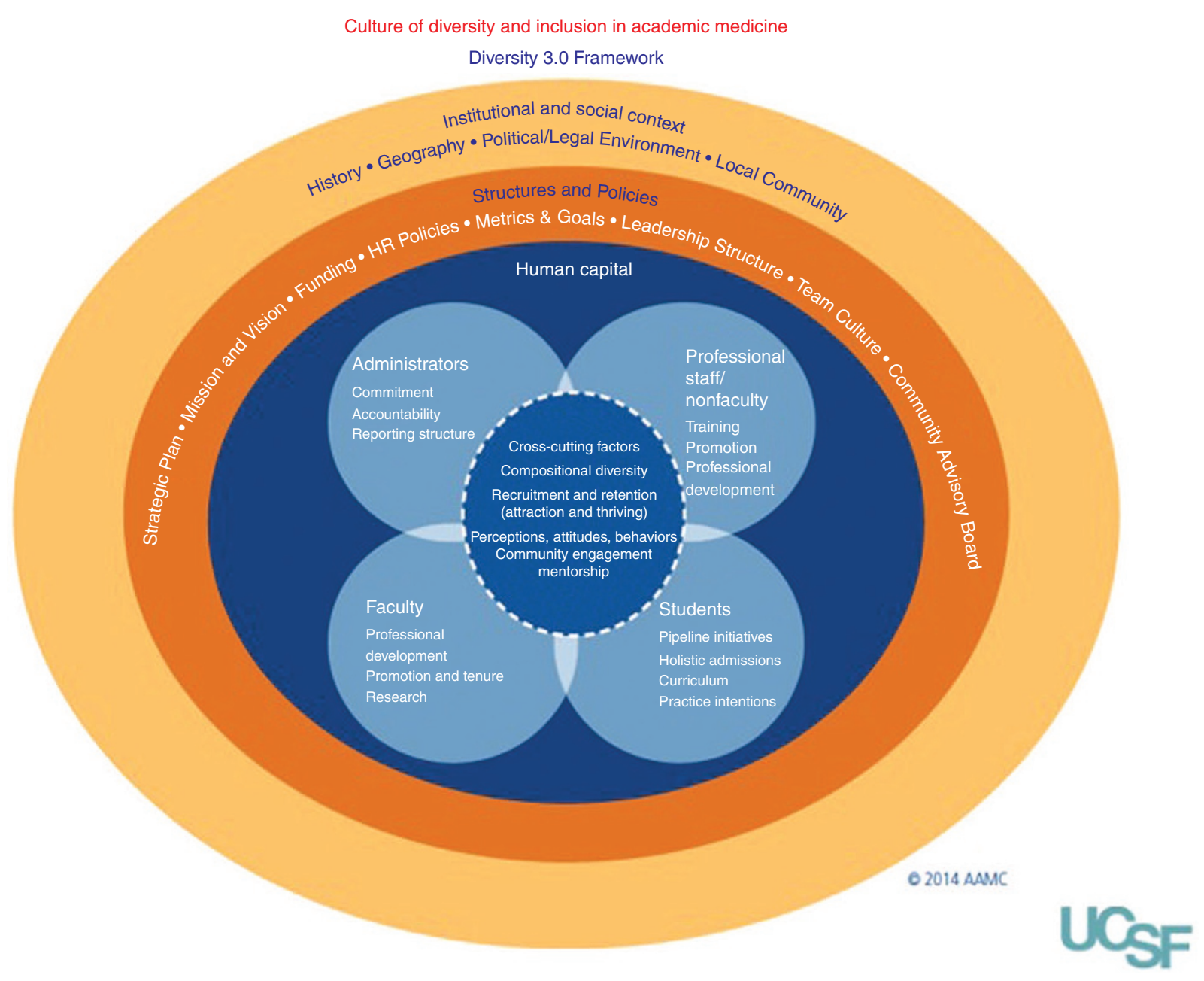

Figure 2. The Association of American Medical Colleges developed the diversity 3.0 Framework in order to view diversity and inclusion as solutions instead of problems. Reprinted with permission from the Association of American Medical Colleges. 
of investigator initiated research. We must also improve workforce utilization and training by reducing the need for external salary support and improve training at the graduate and postdoctoral levels. We have opportunities to impact NIH direction through the NIH Blueprint and through reallocation of dollars unspent by the National Children's Study.

Improving our workforce means paying attention to promoting diversity. Women and minorities constitute the only growing population of domestic doctoral graduates and we need a large pool of candidates for future excellence. We are still struggling in our workforce. Looking at data from the AAMC in their report last year of US Physicians by graduation year, race, ethnicity and sex over the past 3 decades, white men and women lead the ranks and Hispanics, blacks and Native Americans fall behind substantially over all these years (14).

A closer look shows that in regard to NIH research projects, although there has been significant growth of Asian and Hispanic awardees, the numbers for Black and Native Americans are disappointing whether it is broken down by MD degrees or MD PhD degrees. When we look at our diversity breakdown as a function of age, we are doing a bit better in the younger age groups as we pay more attention to this problem and fix the leaks in our pipeline.

Diversity also means thinking about sexual orientation issues. In a recent report from a Group on Diversity and Inclusion (GDI) meeting in Toronto, faculty surveyed at UCLA declared only 4\% were Lesbian Gay Bisexual Transgender (LGBT) (presented in part at "LGBT Faculty: Perceptions Regarding Growth Opportunities and Promotion Equality." GDI Annual Meeting, Toronto, Canada, 2013) (14).

At my institution, LGBT make up $7 \%$ of our faculty with national and California stats as noted. We also have to consider persons with disabilities that make up $19 \%$ of the workforce. There will be federal guidelines soon for this group as well as veterans, especially with the increasing numbers of women in our armed forces.

The AAMC developed the Diversity 3.0 Framework designed to support innovative, high performing organizations by promoting a culture of inclusion and a full appreciation of different perspectives. Diversity 3.0 integrates activities and policies into core organizational strategies. It views diversity and inclusion as solutions instead of problems (15) (Figure 2).

- Institutional and social context: The external forces that affect people and processes within institutions that shape expectations and experiences. Factors that influence culture such as history, geography, political and legal environment, and local community fall in this dimension.

- Structures and policies: The processes, practices, and procedures within institutions that act as barriers or accelerators of culture. Such factors include the institution's strategic plan, mission and vision, funding, human resources policies, metrics and goals, leadership structure, team culture, and the community advisory board.
- Human capital: The people-administrators, faculty, professional staff/non-faculty and students-make the place. Compositional diversity, recruitment and retention, perceptions, attitudes, behaviors, community engagement, and mentorship determine culture. There are particular issues facing each of these groups that are important components of culture. For example, professional development programs for faculty represent an important facet of culture.

So how do we renovate our pediatric house? We can provide clear leadership in changing institutional culture and structure as part of our strategic planning. We can remedy inequities in hiring, promotion and treatment. We can hold leadership workshops and require evidence for equitable practices before approving appointments. Most importantly, we need to develop and implement policies accounting for flexibility across the life course. We need to provide resources to our aspiring leaders and train them in unconscious bias. Mentoring and coaching programs should abound. It is important to find out what your faculty think about your institution's climate. And then we must advocate and sponsor as it says in our American Pediatric Society mission that I mentioned at the beginning of the talk. So I put forth our challenge to all of you, to support, encourage inspire and motivate at least one young academic pediatrician.

\section{REFERENCES}

1. Barkin SL, Fuentes-Afflick E, Brosco JP, Tuchman AM. Unintended consequences of the Flexner report: women in pediatrics. Pediatrics 2010;126:1055-7.

2. MIT School of Science and School of Engineering Faculty Committee. A Report on the Status of Women Faculty in the Schools of Science and Engineering at MIT. School of Science and School of Engineering, Massachusetts Institute of Technology: Cambridge, MA, 2011. pp. 34.

3. Blickenstaff JC. Women and Science Careers: Leaky Pipeline or Gender Filter? Gender and Education 2005 17:369-86.

4. Moss-Racusin CA, Dovidio JF, Brescoll VL, Graham MJ, Handelsman J. Science faculty's subtle gender biases favor male students. Proc Natl Acad Sci USA 2012;109:16474-9.

5. Carnes M, Devine PG, Baier Manwell L, et al. The effect of an intervention to break the gender bias habit for faculty at one institution: a cluster randomized, controlled trial. Acad Med 2015;90:221-30.

6. UC Faculty Family Friendly Edge. Academic Pipeline Project; Mason MA, Golden M, Frasch K. Leaks in the Academic Pipeline for Women. The UC Faculty Family Friendly Edge, The University of California Faculty Family Friendly Edge, 2003 http://ucfamilyedge.berkeley.edu.

7. Physician-Scientist Workforce Working Group; Ginsburg D, Mills S, Shurin S et al. Physician-Scientist Workforce Working Group Report. National Institutes of Health: Bethesda, MD, 2014.

8. Lautenberger DM, Dandar VM, Raezer C, Sloane RA. The State of Women in Academic Medicine: the Pipeline and Pathways to Leadership 20132014. Association of American Medical Colleges: Washington, D.C., 2014. pp. 18.

9. Lautenberger D, Raezer C, Bunton SA. The Underrepresentation of Women in Leadership Positions at U.S. Medical Schools AAMC Analysis in Brief. Association of American Medical Colleges, 2015.

10. McGregor H. Mrs Moneypenny's Careers Advice for Ambitious Women. Portfolio/Penguin: New York, 2012. pp. 304.

11. DeAngelis C. Women in pediatrics. JAMA Pediatr 2015;169:106-7.

12. American Academy of Arts and Sciences (AAAS) IoS, Enginering \& Technology Oversight Committee; Lane N, Augustine NR, Bryson JE et al. 


\section{American Pediatric Society 2015 Presidential Address

Restoring the Foundation: The Vital Role of Research in Preserving the American Dream. American Academy of Arts and Sciences (AAAS): Cambridge, MA, 2014.

13. FASEB Federation of American Societies for Experimental Biology; Antin PB, Drehman B, Garrison H, Seger Y, Haywood JR. Sustaining Discovery in Biological and Medical Sciences: A Framework for Discussion. FASEB Federation of American Societies for Experimental Biology: Bethesda, MD, 2015.
14. AAMC Association of American Medical Colleges 2014 Diversity in the Physician Workforce: Facts \& Figures 2014, Section II: Current Status of U.S. Physician Workforce. Facts \& Figures Data Series. AAMC Association of American Medical Colleges: Washington, D.C.

15. Association of American Medical Colleges, Culture and Climate Assessment Workgroup 2014 Part I: Diversity 3.0 Framework. Assessing Institutional Culture and Climate. Webcast Supplemental Guide. 